\title{
Testing for Linear and Nonlinear Granger Causality in the Real Exchange Rate-Consumption Relation
}

\author{
Efthymios G. Pavlidis, Ivan Paya, and David A. Peel \\ Department of Economics, Lancaster University Management School, UK
}

\begin{abstract}
International real business cycle models predict a relationship between real exchange rates and consumption. This prediction is not supported by the empirical literature. In a new approach, we apply nonlinear Granger-causality tests to data for 14 OECD countries.
\end{abstract}

Keywords: Nonlinear Granger Causality, Real Exchange Rates, Consumption, Heteroskedasticity Robust Test

JEL Classification: C2, F31

\section{Introduction}

International Real Business Cycle (IRBC) models predict a relationship between the real exchange rate and real consumption. With unrestricted trading in complete asset markets and with time-separable and iso-elastic preferences, international risk sharing implies that relative prices are proportional to the ratio of marginal utilities of consumption (Backus and Smith, 1993). As a consequence, a depreciation of the real exchange is associated with an increase in real consumption in the home country relative to the foreign. ${ }^{1}$

Despite the strong theoretical foundations of IRBC models, the empirical evidence in favor of a relationship between real exchange rate movements and changes in real consumption is only limited (Head et al., 2004). This finding implies the lack of international risk sharing

\footnotetext{
${ }^{*}$ Correspondence: Efthymios G. Pavlidis, Department of Economics, Lancaster University Management School, LA1 4YX, UK. E-mail: e.pavlidis@lancaster.ac.uk

${ }^{1}$ A relationship between the real exchange rate and consumption series exists even if the assumptions of standard IRBC models are relaxed, and other features are introduced into the model, such as incomplete capital markets, sticky prices in local currency pricing, and habits (Benigno and Thoenissen, 2008; Chari et al., 2002; Head et al., 2004).
} 
across countries and is considered as one of the major puzzles of international economics (Obstfeld and Rogoff, 2000).

A common feature of most of the empirical IRBC studies to date is the linear modeling framework. An alternative strand of literature demonstrates how the presence of trade costs in equilibrium models of real exchange rate determination can induce nonlinear but mean reverting adjustment toward the equilibrium value (Dumas, 1992). In a number of early empirical contributions this type of nonlinear behavior has been parsimoniously captured by threshold and smooth transition autoregressive models (see, e.g., Sollis, 2005). These earlier studies assume the equilibrium real exchange rate to be constant. More recent studies extend the nonlinear analysis to allow for a time-varying equilibrium given by economic fundamentals (Lothian and Taylor, 2008).

In the spirit of Lothian and Taylor (2008), this letter extends the empirical IRBC literature by applying a nonlinear Granger-causality test to real exchange rate and real consumption data. An appealing feature of the test is that it is powerful under a variety of nonlinear data generating processes. Hence, there is no need for the researcher to specify the exact type of nonlinearity. Moreover, heteroskedasticity-robust versions of the test have been proposed in the literature which exhibit good size and power properties (Pavlidis et al., 2013).

\section{Causality Tests}

Let $\left\{y_{t}\right\}$ and $\left\{x_{t}\right\}$ denote two stationary and ergodic time series processes. We are interested in examining whether there is a Granger-causal relationship between the two series without restricting the analysis to a specific functional form. For this purpose, we employ a testing framework which is encompassed within Godfrey's (1988, Ch. 4.3) general framework for testing for incorrect functional form. ${ }^{2}$

Consider the following regression equation as a general representation of the Grangercausal relation between $\left\{y_{t}\right\}$ and $\left\{x_{t}\right\}$ :

$$
y_{t}=f\left(y_{t-1}, \ldots, y_{t-p_{1}}, x_{t-1}, \ldots, x_{t-q_{1}} ; \boldsymbol{\theta}\right)+e_{t}
$$

where $\boldsymbol{\theta}$ is a vector of parameters, $\boldsymbol{e}$ is a vector of serially uncorrelated and homoskedastic normal errors, and $f(\cdot)$ is a continuously differentiable function. To ease notation, let $q_{1} \leq k$

\footnotetext{
${ }^{2}$ We are grateful to the referee for drawing our attention to the work of Godfrey (1988).
} 
and $p_{1} \leq k$. Taking a $k$-order Taylor series expansion of $f(\cdot)$ yields:

$$
\begin{aligned}
y_{t} & =\phi_{0}+\sum_{j=1}^{p_{1}} \phi_{j} y_{t-j}+\sum_{j=1}^{q_{1}} \psi_{j} x_{t-j} \\
& +\sum_{j_{1}=1}^{p_{1}} \sum_{j_{2}=j_{1}}^{p_{1}} \phi_{j_{1} j_{2}} y_{t-j_{1}} y_{t-j_{2}}+\sum_{j_{1}=1}^{p_{1}} \sum_{j_{2}=1}^{q_{1}} \delta_{j_{1} j_{2}} y_{t-j_{1}} x_{t-j_{2}} \\
& +\sum_{j_{1}=1}^{q_{1}} \sum_{j_{2}=j_{1}}^{q_{1}} \psi_{j_{1} j_{2}} x_{t-j_{1}} x_{t-j_{2}}+\cdots+\sum_{j_{1}=1}^{p_{1}} \sum_{j_{2}=j_{1}}^{q_{1}} \cdots \sum_{j_{k}=j_{k-1}}^{p_{1}} \phi_{j_{1} \cdots j_{k}} y_{t-j_{1}} \cdots y_{t-j_{k}} \\
& +\sum_{j_{1}=1}^{q_{1}} \sum_{j_{2}=j_{1}}^{q_{1}} \cdots \sum_{j_{k}=j_{k-1}}^{q_{1}} \psi_{j_{1} \cdots j_{k}} x_{t-j_{1}} \cdots x_{t-j_{k}}+u_{t},
\end{aligned}
$$

where $u_{t}=e_{t}+R_{k}\left(y_{t}, x_{t}\right)$ with $R_{k}(\cdot)$ denoting the remainder term of the Taylor series expansion. The above regression equation is particularly appealing because it can approximate a variety of nonlinear modes, such as smooth transition and bilinear models, and it also nests the equation for its linear counterpart. It is easy to see that equation (2) includes all combinations between lagged $y$ s and $x$ s. Under the null hypothesis that $x$ fails to Granger cause $y$, $x \stackrel{\text { N.G.C. }}{\longrightarrow} y$, all coefficients on the terms that include lagged $x$ s are zero:

$H_{0}:\left\{\begin{array}{lll}\psi_{j}=0, & j=1, \ldots, q_{1}, & \\ \delta_{j_{1} j_{2}}=0, & j_{1}=1, \ldots, p_{1}, & j_{2}=1, \ldots, q_{1} \\ \psi_{j_{1} j_{2}}=0, & j_{1}=1, \ldots, q_{1}, & j_{2}=j_{1}, \ldots, q_{1} \\ & \vdots \\ \psi_{j_{1} \ldots j_{2}}=0, & j_{1}=1, \ldots, q_{1}, & j_{2}=j_{1}, \ldots, q_{1}, \ldots, j_{k}=j_{k-1}, \ldots, q_{1}\end{array}\right.$

Given the assumption of homoskedasticity, this null hypothesis can be examined by using standard Wald $F$-tests. However, if the homoskedasticity assumption is not satisfied then standard $F$-tests can frequently lead to false rejections of the null (Vilasuso, 2001).

Pavlidis et al. (2013) examine the performance of several heteroskedasticity robustification methods for both linear and nonlinear Granger-causality tests. Their findings show that the Heteroskedasticity-Consistent-Covariance-Matrix Estimator (HCCME) of MacKinnon and White (1985) and the Fixed Design Wild Bootstrap (FDWB) perform well both in terms of size and power. Hence, these methods constitute a feasible solution for drawing valid statistical inference. The FDWB method is particularly attractive because, in addition to heteroskedastic errors, it also allows for deviations from normality such as excess kurtosis, commonly found in real exchange rate regression errors. For a detailed description of the HCCME and FDWB methods, we refer the interested reader to Pavlidis et al. (2013). 


\section{Empirical Results}

Our dataset consists of quarterly data for nominal exchange rates, $S$, consumer prices, $P$, and nominal private consumption series, $N C$, for 14 OECD countries: Austria, Australia, Canada, Denmark, Finland, France, Italy, Japan, Norway, Netherlands, Sweden, Switzerland, the United Kingdom (UK), and the United States (US), with the latter acting as the reference country. All data are obtained from the International Financial Statistics database.

The sample period differs across countries (as can be seen from Table 1) with the differences being due to data availability. The longest period is from 1957Q1 to 2010Q4 and the shortest from 1977Q1 to 1998Q4. We note that, for many country pairs, the data start before the collapse of the Bretton Woods system in the early 1970s. Thus, the period under examination spans both a fixed and a floating exchange rate regime. Following Mussa (1986), several studies have shown that changes in exchange rate regimes are associated with substantial changes in real exchange rate volatility. In particular, real exchange rates, similarly to nominal rates, are more volatile during floating than during fixed regimes. In our context, the well-documented increase in the volatility of real exchange rates after the collapse of the Bretton Woods system highlights the importance of using heteroskedasticity-robust Granger-causality tests.

We follow Backus and Smith (1993) and work with first differences of the log real exchange rate, log real consumption, and relative consumption. The log real exchange rate, $\log$ real consumption, and relative consumption for country $j$ are defined as $q_{j}=$ $\log \left(S_{j} \times P_{j} / P_{\mathrm{US}}\right), c_{j}=\log \left(N C_{j} / P_{j}\right)$, and $\tilde{c}_{j}=c_{\mathrm{US}}-c_{j}$, respectively. Table 1 presents the results of the linear and nonlinear Granger-causality tests based on LS, HCCME, and FDWB. Overall, the results are supportive of a Granger-causal relationship between real exchange rates and real consumption. For the majority of country pairs (10 out of 13) the null of no-Granger causality is rejected by a heteroskedasticity-robust test at least once at the 10 percent significance level. The results do not reveal a clear pattern of the direction of Granger causality. For Austria and Norway, Granger causality runs from consumption and/or relative consumption series to the real exchange rate. For Finland, Japan, and Netherlands, it runs in the opposite direction. Finally, for Canada, Denmark, Sweden, Switzerland, and the UK, there is evidence in favor of bidirectional Granger causality.

\section{INSERT TABLE 1}

Turning to the presence of nonlinearities in the data, we observe cases where the nonlinear test can detect Granger causality, while its linear counterpart fails to do so (e.g., Austria, Norway). However, in other cases the opposite is true (e.g., Japan). What is important is that the application of the nonlinear test substantially increases the number of rejections of the null (from 12 to 23), which supports the presence of nonlinearities in the data generating process. These findings are complementary to those of Stockman (1998) and Lothian 
and Taylor (2008), who focus on the production side of the economy and show that statistically significant relationships between real exchange rates and output exist when allowance is made for nonlinearities.

On the basis of our results, it seems promising for future research to investigate the specific type of nonlinearities that characterize the relationship between the real exchange rate and consumption. It would also be interesting for future research to examine the impact of nonlinearity on the performance of the linear procedures that have been employed so far in the IRBC literature. This exercise could provide an explanation for the discouraging results reported by previous research (Head et al., 2004).

Before concluding, we note that our results are only indicative about the validity of IRBC models. On the one hand, rejection of the null of no-Granger causality does not necessarily imply an empirical relationship in line with standard IRBC models. On the other hand, Granger-causality tests exhibit moderate power for some of the sample sizes employed in this paper and, therefore, failure to reject the null cannot be considered as strong evidence against these models.

\section{Conclusion}

Empirical studies that adopt a linear framework typically fail to find evidence in favor of a relationship between the real exchange rate and consumption. In this paper, we extended the analysis by applying both linear and nonlinear Granger-causality tests to data for 14 OECD countries. Our results show that allowing for nonlinearities increases substantially the number of rejections of the null hypothesis of no-Granger causality.

\section{References}

Backus, D. and Smith, G. (1993), "Consumption and Real Exchange Rates in Dynamic Economies With Non-Traded Goods," Journal of International Economics, 35, 297-316.

Benigno, G. and Thoenissen, C. (2008), "Consumption and real exchange rates with incomplete markets and non-traded goods," Journal of International Money and Finance, 27, 926-948.

Chari, V., Kehoe, P., and McGrattan, E. (2002), "Can Sticky Price Models Generate Volatile and Persistent Real Exchange Rates?” Review of Economic Studies, 69, 533-63.

Dumas, B. (1992), "Dynamic Equilibrium and the Real Exchange Rate in Spatially Separated World," Review of Financial Studies, 5, 153-180.

Godfrey, L. (1988), Misspecification Tests in Econometrics: The Lagrange Mutliplier Principle and Other Approaches, London: James Nisbet and Cambridge University Press. 
Head, A., Mattina, T., and Smith, G. (2004), "Real Exchange Rates, Preferences, and Incomplete Markets: Evidence, 1961-2001," Canadian Journal of Economics, 37, 782-801.

Lothian, J. R. and Taylor, M. P. (2008), "Real Exchange Rates Over the Past Two Centuries: How Important is the Harrod-Balassa-Samuelson Effect?" Economic Journal, 118, 17421763.

MacKinnon, J. G. and White, H. (1985), "Some Heteroskedasticity Consistent Covariance Matrix Estimators With Improved Finite Sample Properties," Journal of Econometrics, 29, 305-325.

Mussa, M. (1986), "Nominal Exchange Rate Regimes and the Behaviour of Real Exchange Rates: Evidence and Implications," Carnegie-Rochester Conference Series on Public Policy, 25, 117-214.

Obstfeld, M. and Rogoff, K. S. (2000), "The Six Major Puzzles in International Macroeconomics: Is There a Common Cause?” NBER Working Papers, No. 7777.

Pavlidis, E. G., Paya, I., and Peel, D. A. (2013), "Nonlinear Causality Tests and Multivariate Conditional Heteroskedasticity: A Simulation Study," Studies in Nonlinear Dynamics \& Econometrics, 17, 297-312.

Sollis, R. (2005), "Evidence on Purchasing Power Parity from Univariate Models: The Case of Smooth Transition Trend-stationarity," Journal of Applied Econometrics, 20, 79-98.

Stockman, A. C. (1998), "New evidence connecting exchange rates to business cycles," Economic Quarterly, 73-89.

Vilasuso, J. R. (2001), "Causality tests and Conditional Heteroskedasticity: Monte Carlo evidence," Journal of Econometrics, 101, 25-35. 


\section{Tables}

Table 1: Linear and Nonlinear Granger-Causality Tests

\begin{tabular}{|c|c|c|c|c|c|c|}
\hline \multirow[b]{2}{*}{ Hypothesis } & \multicolumn{3}{|c|}{ Linear } & \multicolumn{3}{|c|}{ Nonlinear } \\
\hline & $F_{L S}$ & $F_{H C C M E}$ & $F_{F D W B}$ & $F_{L S}$ & $F_{H C C M E}$ & $F_{F D W B}$ \\
\hline & \multicolumn{6}{|c|}{ Australia, 1959Q3 to 2010Q4 } \\
\hline$\Delta c_{j} \stackrel{\text { N.G.C. }}{\longrightarrow} \Delta q_{j}$ & 1.94 & 1.12 & 1.94 & $2.17 * *$ & 0.87 & 2.17 \\
\hline$\Delta c_{\mathrm{US}} \stackrel{\text { N.G.C. }}{\longrightarrow} \Delta q_{j}$ & 0.57 & 0.54 & 0.57 & 1.24 & 0.80 & 1.24 \\
\hline$\Delta \tilde{c}_{j} \stackrel{\text { N.G.C. }}{\longrightarrow} \Delta q_{j}$ & 0.97 & 1.09 & 0.97 & 1.35 & 0.92 & 1.35 \\
\hline$\Delta q_{j} \stackrel{\text { N.G.C. }}{\longrightarrow} \Delta c_{j}$ & 0.12 & 0.11 & 0.12 & 1.39 & 0.84 & 1.39 \\
\hline$\Delta q_{j} \stackrel{\text { N.G.C. }}{\longrightarrow} \Delta c_{\mathrm{US}}$ & 0.82 & 1.11 & 0.82 & 0.70 & 0.85 & 0.70 \\
\hline$\Delta q_{j} \stackrel{\text { N.G.C. }}{\longrightarrow} \Delta \tilde{c}_{j}$ & 0.70 & 0.55 & 0.70 & 1.07 & 0.77 & 1.07 \\
\hline & \multicolumn{6}{|c|}{ Austria, 1957Q1 to 2010Q4 } \\
\hline$\Delta c_{j} \stackrel{\text { N.G.C. }}{\longrightarrow} \Delta q_{j}$ & 1.50 & 1.93 & 1.50 & $1.43 *$ & 1.03 & $1.43 *$ \\
\hline$\Delta c_{\mathrm{US}} \stackrel{\text { N.G.C. }}{\longrightarrow} \Delta q_{j}$ & 1.55 & 1.00 & 1.55 & $2.10 * *$ & 1.13 & $2.10 *$ \\
\hline$\Delta \tilde{c}_{j} \stackrel{\text { N.G.C. }}{\longrightarrow} \Delta q_{j}$ & 0.31 & 0.31 & 0.31 & $2.02 * *$ & $1.47 *$ & $2.02 * *$ \\
\hline$\Delta q_{j} \stackrel{\text { N.G.C. }}{\longrightarrow} \Delta c_{j}$ & 0.74 & 1.03 & 0.74 & 0.97 & 1.00 & 0.97 \\
\hline$\Delta q_{j} \stackrel{\text { N.G.C. }}{\longrightarrow} \Delta c_{\mathrm{US}}$ & 1.96 & 1.39 & 1.96 & 1.38 & 0.94 & 1.38 \\
\hline$\Delta q_{j} \stackrel{\text { N.G.C. }}{\longrightarrow} \Delta \tilde{c}_{j}$ & 0.50 & 0.60 & 0.50 & 0.64 & 0.88 & 0.64 \\
\hline & \multicolumn{6}{|c|}{ Canada, 1957Q1 to 2010Q4 } \\
\hline$\Delta c_{j} \stackrel{\text { N.G.C. }}{\longrightarrow} \Delta q_{j}$ & 0.91 & 0.77 & 0.91 & $1.56^{* *}$ & 0.66 & 1.56 \\
\hline$\Delta c_{\mathrm{US}} \stackrel{\text { N.G.C. }}{\longrightarrow} \Delta q_{j}$ & 1.45 & 1.40 & 1.45 & $1.92 * *$ & 1.15 & $1.92 *$ \\
\hline$\Delta \tilde{c}_{j} \stackrel{\text { N.G.C. }}{\longrightarrow} \Delta q_{j}$ & 0.36 & 0.61 & 0.36 & 1.30 & 1.05 & 1.30 \\
\hline$\Delta q_{j} \stackrel{\text { N.G.C. }}{\longrightarrow} \Delta c_{j}$ & $2.98 * *$ & $5.16^{* *}$ & $2.98 * *$ & $1.46^{*}$ & $1.53 * *$ & $1.46^{* *}$ \\
\hline$\Delta q_{j} \stackrel{\text { N.G.C. }}{\longrightarrow} \Delta c_{\mathrm{US}}$ & 0.87 & 1.55 & 0.87 & 1.02 & 0.94 & 1.02 \\
\hline$\Delta q_{j} \stackrel{\text { N.G.C. }}{\longrightarrow} \Delta \tilde{c}_{j}$ & 1.30 & 1.71 & $1.30 *$ & 0.68 & 0.57 & 0.68 \\
\hline & \multicolumn{6}{|c|}{ Denmark, 1977Q1 to 2010Q4 } \\
\hline$\Delta c_{j} \stackrel{\text { N.G.C. }}{\longrightarrow} \Delta q_{j}$ & 1.57 & 1.81 & 1.57 & 0.79 & 0.89 & 0.79 \\
\hline$\Delta c_{\mathrm{US}} \stackrel{\text { N.G.C. }}{\longrightarrow} \Delta q_{j}$ & 0.43 & 0.32 & 0.43 & $1.45^{*}$ & $1.86 * *$ & 1.45 \\
\hline$\Delta \tilde{c}_{j} \stackrel{\text { N.G.C. }}{\longrightarrow} \Delta q_{j}$ & 1.03 & 1.26 & 1.03 & 1.06 & 0.76 & $1.06^{*}$ \\
\hline$\Delta q_{j} \stackrel{\text { N.G.C. }}{\longrightarrow} \Delta c_{j}$ & $3.32 * *$ & $2.69 * *$ & $3.32 * *$ & $1.55^{*}$ & $1.51 *$ & 1.55 \\
\hline$\Delta q_{j} \stackrel{\text { N.G.C. }}{\longrightarrow} \Delta c_{\mathrm{US}}$ & 1.50 & 1.50 & 1.50 & 1.17 & 0.62 & 1.17 \\
\hline $\begin{array}{l}\Delta q_{j} \stackrel{\text { N.G.C. }}{\longrightarrow} \Delta \tilde{c}_{j} \\
\text { Continued on } \mathrm{N}\end{array}$ & 1.74 & 1.49 & 1.74 & 0.79 & 0.46 & 0.79 \\
\hline
\end{tabular}


Table 1 - Continued

\begin{tabular}{|c|c|c|c|c|c|c|}
\hline \multirow[b]{2}{*}{ Hypothesis } & \multicolumn{3}{|c|}{ Linear } & \multicolumn{3}{|c|}{ Nonlinear } \\
\hline & $F_{L S}$ & $F_{H C C M E}$ & $F_{F D W B}$ & $F_{L S}$ & $F_{H C C M E}$ & $F_{F D V}$ \\
\hline & \multicolumn{6}{|c|}{ Finland, 1970Q1 to 1998Q4 } \\
\hline$\Delta c_{j} \stackrel{\text { N.G.C. }}{\longrightarrow} \Delta q_{j}$ & 0.48 & 0.32 & 0.48 & 0.44 & 0.41 & 0.44 \\
\hline$\Delta c_{\mathrm{US}} \stackrel{\text { N.G.C. }}{\longrightarrow} \Delta q_{j}$ & 0.95 & 1.51 & 0.95 & 1.07 & 1.12 & 1.07 \\
\hline$\Delta \tilde{c}_{j} \stackrel{\text { N.G.C. }}{\longrightarrow} \Delta q_{j}$ & 0.19 & 0.24 & 0.19 & 0.50 & 0.84 & 0.50 \\
\hline$\Delta q_{j} \stackrel{\text { N.G.C. }}{\longrightarrow} \Delta c_{j}$ & 0.19 & 0.28 & 0.19 & 0.62 & 0.31 & 0.62 \\
\hline$\Delta q_{j} \stackrel{\text { N.G.C. }}{\longrightarrow} \Delta c_{\mathrm{US}}$ & 1.75 & $2.27 *$ & $1.75^{* *}$ & 1.20 & 0.92 & $1.20 *$ \\
\hline$\Delta q_{j} \stackrel{\text { N.G.C. }}{\longrightarrow} \Delta \tilde{c}_{j}$ & 0.34 & 0.45 & 0.34 & 0.67 & 0.58 & 0.67 \\
\hline
\end{tabular}

$\Delta c_{j} \stackrel{\text { N.G.C. }}{\longrightarrow} \Delta q_{j}$

$\Delta c_{\text {US }} \stackrel{\text { N.G.C. }}{\longrightarrow} \Delta q_{j}$

$\Delta \tilde{c}_{j} \stackrel{\text { N.G.C. }}{\longrightarrow} \Delta q_{j}$

$\Delta q_{j} \stackrel{\text { N.G.C. }}{\longrightarrow} \Delta c_{j}$

$\Delta q_{j} \stackrel{\text { N.G.C. }}{\longrightarrow} \Delta c_{\mathrm{US}}$

$\Delta q_{j} \stackrel{\text { N.G.C. }}{\longrightarrow} \Delta \tilde{c}_{j}$

$\Delta c_{j} \stackrel{\text { N.G.C. }}{\longrightarrow} \Delta q_{j}$

$\Delta c_{\text {US }} \stackrel{\text { N.G.C. }}{\longrightarrow} \Delta q_{j}$

$\Delta \tilde{c}_{j} \stackrel{\text { N.G.C. }}{\longrightarrow} \Delta q_{j}$

$\Delta q_{j} \stackrel{\text { N.G.C. }}{\longrightarrow} \Delta c_{j}$

$\Delta q_{j} \stackrel{\text { N.G.C. }}{\longrightarrow} \Delta c_{\mathrm{US}}$

$\Delta q_{j} \stackrel{\text { N.G.C. }}{\longrightarrow} \Delta \tilde{c}_{j}$

$\Delta c_{j} \stackrel{\text { N.G.C. }}{\longrightarrow} \Delta q_{j}$

$\Delta c_{\text {US }} \stackrel{\text { N.G.C. }}{\longrightarrow} \Delta q_{j}$

$\Delta \tilde{c}_{j} \stackrel{\text { N.G.C. }}{\longrightarrow} \Delta q_{j}$

$\Delta q_{j} \stackrel{\text { N.G.C. }}{\longrightarrow} \Delta c_{j}$

$\Delta q_{j} \stackrel{\text { N.G.C. }}{\longrightarrow} \Delta c_{\mathrm{US}}$

$\Delta q_{j} \stackrel{\text { N.G.C. }}{\longrightarrow} \Delta \tilde{c}_{j}$

$\Delta c_{j} \stackrel{\text { N.G.C. }}{\longrightarrow} \Delta q_{j}$

Continued on Next Page

\section{France, 1970Q1 to $1998 Q 4$}

0.57

$0.97 \quad 0.84$

0.97

0.89

1.46

1.11

1.46

$0.25 \quad 0.27$

0.25

1.30

1.27

1.30

$1.36 \quad 1.99$

1.36

0.77

1.01

0.77

$0.67 \quad 0.78$

0.67

0.98

0.41

0.98

$0.87 \quad 0.80$

0.87

0.79

0.62

0.79

\section{Italy, 1970Q1 to 1998Q4}

$\begin{array}{llllll}0.43 & 0.30 & 0.43 & 0.75 & 0.69 & 0.75 \\ 0.59 & 0.55 & 0.59 & 1.53 * & 0.94 & 1.53 \\ 0.35 & 0.22 & 0.35 & 1.17 & 0.66 & 1.17 \\ 1.26 & 0.95 & 1.26 & 1.12 & 0.82 & 1.12 \\ 1.05 & 1.48 & 1.05 & 0.89 & 0.57 & 0.89 \\ 1.48 & 1.23 & 1.48 & 1.06 & 0.62 & 1.06\end{array}$

\section{Japan, 1957Q1 to 2010Q4}

$\begin{array}{llllll}0.27 & 0.32 & 0.27 & 1.15 & 0.54 & 1.15 \\ 0.58 & 0.56 & 0.58 & 0.85 & 0.68 & 0.85\end{array}$

$\begin{array}{lll}0.58 & 0.56 & 0.58\end{array}$

$\begin{array}{ll}0.85 & 0.68\end{array}$

0.85

$0.23 \quad 0.21$

0.23

$1.13 \quad 0.50$

1.13

$1.59 \quad 1.41$

1.59

1.04

0.72

1.04

$2.09 * 1.98 * 2.09 *$

0.95

0.64

0.95

$1.29 \quad 1.32$

1.29

0.81

0.63

0.81

Netherlands, 1977Q1 to 1998Q4

$0.43 \quad 0.34$

0.43

1.21

0.61

1.21 
Table 1 - Continued

\begin{tabular}{|c|c|c|c|c|c|c|}
\hline \multirow[b]{2}{*}{ Hypothesis } & \multicolumn{3}{|c|}{ Linear } & \multicolumn{3}{|c|}{ Nonlinear } \\
\hline & $F_{L S}$ & $F_{H C C M E}$ & $F_{F D W B}$ & $F_{L S}$ & $F_{H C C M E}$ & $F_{F D W B}$ \\
\hline$\Delta c_{\mathrm{US}} \stackrel{\text { N.G.C. }}{\longrightarrow} \Delta q_{j}$ & 0.98 & 0.68 & 0.98 & 0.87 & 0.40 & 0.87 \\
\hline$\Delta \tilde{c}_{j} \stackrel{\text { N.G.C. }}{\longrightarrow} \Delta q_{j}$ & 0.40 & 0.28 & 0.40 & 1.40 & 0.74 & 1.40 \\
\hline$\Delta q_{j} \stackrel{\text { N.G.C. }}{\longrightarrow} \Delta c_{j}$ & 1.82 & $2.13^{*}$ & $1.82 *$ & 0.89 & 0.69 & 0.89 \\
\hline$\Delta q_{j} \stackrel{\text { N.G.C. }}{\longrightarrow} \Delta c_{\mathrm{US}}$ & 1.20 & 1.08 & 1.20 & 0.91 & 0.32 & 0.91 \\
\hline$\Delta q_{j} \stackrel{\text { N.G.C. }}{\longrightarrow} \Delta \tilde{c}_{j}$ & 0.61 & 0.67 & 0.61 & 0.72 & 0.59 & 0.72 \\
\hline & \multicolumn{6}{|c|}{ Norway, 1961Q1 to 2010Q4 } \\
\hline$\Delta c_{j} \stackrel{\text { N.G.C. }}{\longrightarrow} \Delta q_{j}$ & 1.03 & 0.74 & 1.03 & 0.55 & 0.35 & 0.55 \\
\hline$\Delta c_{\mathrm{US}} \stackrel{\text { N.G.C. }}{\longrightarrow} \Delta q_{j}$ & 0.41 & 0.34 & 0.41 & $2.14 * *$ & $2.18 * *$ & $2.14 * *$ \\
\hline$\Delta \tilde{c}_{j} \stackrel{\text { N.G.C. }}{\longrightarrow} \Delta q_{j}$ & 0.38 & 0.41 & 0.38 & 0.95 & 0.83 & 0.95 \\
\hline$\Delta q_{j} \stackrel{\text { N.G.C. }}{\longrightarrow} \Delta c_{j}$ & 0.75 & 0.65 & 0.75 & 0.87 & 1.19 & 0.87 \\
\hline$\Delta q_{j} \stackrel{\text { N.G.C. }}{\longrightarrow} \Delta c_{\mathrm{US}}$ & 0.57 & 0.48 & 0.57 & 0.85 & 1.06 & 0.85 \\
\hline$\Delta q_{j} \stackrel{\text { N.G.C. }}{\longrightarrow} \Delta \tilde{c}_{j}$ & 0.65 & 0.63 & 0.65 & 0.99 & 0.88 & 0.99 \\
\hline & \multicolumn{6}{|c|}{ Sweden, 1963Q1 to $2010 Q 4$} \\
\hline$\Delta c_{j} \stackrel{\text { N.G.C. }}{\longrightarrow} \Delta q_{j}$ & $2.15^{*}$ & 1.88 & $2.15^{*}$ & 0.68 & 0.53 & 0.68 \\
\hline$\Delta c_{\mathrm{US}} \stackrel{\text { N.G.C. }}{\longrightarrow} \Delta q_{j}$ & 0.45 & 0.50 & 0.45 & $1.92 * *$ & $1.52 *$ & $1.92 * *$ \\
\hline$\Delta \tilde{c}_{j} \stackrel{\text { N.G.C. }}{\longrightarrow} \Delta q_{j}$ & 1.04 & 0.90 & 1.04 & 0.98 & 0.90 & 0.98 \\
\hline$\Delta q_{j} \stackrel{\text { N.G.C. }}{\longrightarrow} \Delta c_{j}$ & $2.07 *$ & 1.92 & $2.07 * *$ & 1.19 & 1.19 & 1.19 \\
\hline$\Delta q_{j} \stackrel{\text { N.G.C. }}{\longrightarrow} \Delta c_{\mathrm{US}}$ & 1.28 & 1.33 & 1.28 & 0.85 & 1.05 & 0.85 \\
\hline$\Delta q_{j} \stackrel{\text { N.G.C. }}{\longrightarrow} \Delta \tilde{c}_{j}$ & 1.15 & 1.60 & 1.15 & 1.05 & 1.30 & 1.05 \\
\hline & \multicolumn{6}{|c|}{ Switzerland, 1970Q1 to 2010Q4 } \\
\hline$\Delta c_{j} \stackrel{\text { N.G.C. }}{\longrightarrow} \Delta q_{j}$ & 1.14 & 1.16 & 1.14 & 0.93 & 1.19 & 0.93 \\
\hline$\Delta c_{\mathrm{US}} \stackrel{\text { N.G.C. }}{\longrightarrow} \Delta q_{j}$ & 0.54 & 0.47 & 0.54 & 1.19 & 1.02 & 1.19 \\
\hline$\Delta \tilde{c}_{j} \stackrel{\text { N.G.C. }}{\longrightarrow} \Delta q_{j}$ & 1.17 & 1.07 & 1.17 & 1.19 & $1.48^{*}$ & 1.19 \\
\hline$\Delta q_{j} \stackrel{\text { N.G.C. }}{\longrightarrow} \Delta c_{j}$ & 0.58 & 0.67 & 0.58 & 1.24 & 1.22 & 1.24 \\
\hline$\Delta q_{j} \stackrel{\text { N.G.C. }}{\longrightarrow} \Delta c_{\mathrm{US}}$ & $3.43 * *$ & $3.95 * *$ & $3.43 * *$ & $1.74 * *$ & 1.28 & $1.74 *$ \\
\hline$\Delta q_{j} \stackrel{\text { N.G.C. }}{\longrightarrow} \Delta \tilde{c}_{j}$ & 1.03 & 1.28 & 1.03 & $1.67 * *$ & $1.47 *$ & $1.67 * *$ \\
\hline & \multicolumn{6}{|c|}{ United Kingdom, 1957Q1 to 2010Q4 } \\
\hline$\Delta c_{j} \stackrel{\text { N.G.C. }}{\longrightarrow} \Delta q_{j}$ & $2.5^{* *}$ & $2.23 *$ & $2.50 *$ & $1.42 *$ & 0.99 & 1.42 \\
\hline$\Delta c_{\mathrm{US}} \stackrel{\text { N.G.C. }}{\longrightarrow} \Delta q_{j}$ & 0.12 & 0.15 & 0.12 & $1.46^{*}$ & $1.84 * *$ & 1.46 \\
\hline$\Delta \tilde{c}_{j} \stackrel{\text { N.G.C. }}{\longrightarrow} \Delta q_{j}$ & $2.50 * *$ & $2.08 *$ & $2.50 * *$ & $1.61 * *$ & $1.50 *$ & 1.61 \\
\hline
\end{tabular}

Continued on Next Page 
Table 1 - Continued

\begin{tabular}{llllllll} 
& \multicolumn{3}{c}{ Linear } & & \multicolumn{3}{c}{ Nonlinear } \\
\cline { 2 - 4 } \cline { 6 - 8 } Hypothesis & $F_{L S}$ & $F_{H C C M E}$ & $F_{F D W B}$ & & $F_{L S}$ & $F_{H C C M E}$ & $F_{F D W B}$ \\
\hline$\Delta q_{j} \stackrel{\text { N.G.C. }}{\longrightarrow} \Delta c_{j}$ & 1.50 & 1.24 & 1.50 & & $1.64^{* *}$ & 1.05 & 1.64 \\
$\Delta q_{j} \stackrel{\text { N.G.C. }}{\longrightarrow} \Delta c_{\text {US }}$ & 1.93 & 1.70 & 1.93 & & 1.24 & 1.10 & 1.24 \\
$\Delta q_{j} \stackrel{\text { N.G.C. }}{\longrightarrow} \Delta \tilde{c}_{j}$ & $2.58^{* *}$ & $2.12^{*}$ & $2.58^{*}$ & & $1.52^{*}$ & 1.18 & 1.52 \\
\hline
\end{tabular}

Notes: The table reports $F$-statistics for the null hypothesis that $x$ does not Granger-cause $y$, $x \stackrel{\text { N.G.C. }}{\longrightarrow} y . q, c$ and $\tilde{c}$ denote the $\log$ of the real exchange rate, real consumption, and relative consumption. $* *$ and $*$ indicate significance at the 5 and 10 percent significance levels, respectively. For all tests, the lag length is set equal to four to exploit annual information. 